\title{
Mobile Learning in Science: A Study in Secondary Education in Greece
}

\author{
Kleopatra Nikolopoulou ${ }^{1}$, Manolis Kousloglou ${ }^{2}$ \\ ${ }^{1}$ Department of Early Childhood Education, School of Education, University of Athens, Athens, Greece \\ ${ }^{2} 3$ rd Junior High School of Kavala, Kavala, Greece \\ Email: klnikolop9@yahoo.gr, klnikolop@ecd.uoa.gr,kusmangr@gmail.com
}

How to cite this paper: Nikolopoulou, K., \& Kousloglou, M. (2019). Mobile Learning in Science: A Study in Secondary Education in Greece. Creative Education, 10, 1271-1284. https://doi.org/10.4236/ce.2019.106096

Received: June 4, 2019

Accepted: June 27, 2019

Published: June 30, 2019

Copyright $\odot 2019$ by author(s) and Scientific Research Publishing Inc. This work is licensed under the Creative Commons Attribution International License (CC BY 4.0).

http://creativecommons.org/licenses/by/4.0/

\begin{abstract}
Mobile technology can facilitate students' learning in anytime, anywhere. Different tools can be used to support science learning, while mobile devices with internet access can facilitate students' online investigations of simulations, video and virtual labs. However, there are few studies that reported mobile supported science activities and this topic is not covered within the Greek context. This paper presents a small scale study from Greece, with examples of mobile technology-supported learning activities in science lessons (in secondary schools). In parallel, it discusses studies on science learning with mobile technology and presents the context of mobile learning in Greece. Implications for educational policy makers, teachers and students are finally discussed.
\end{abstract}

\section{Keywords}

Mobile Learning, Mobile Technology, Mobile Devices, Science, Greece, Secondary Education, Learning Activities, Secondary/High School

\section{Introduction}

There is a widespread ownership of mobile technology, including mobile/ smartphones, tablets, chromebooks, among school-aged youth (Bedesem \& Arner, 2019). Mobile technologies, especially newer, portable handheld devices such as smartphones and tablets allow students to carry out various activities such as, listening to music, watching videos, using a GPS, taking (and editing) photos and videos, taking notes and playing games. The internet is accessed through browsers and many mobile applications (apps), and mobile technologies are being considered as potential teaching and learning tools (Hwang et al., 2018), both within the classroom and beyond. Researchers have called the 
learning mode that employs mobile technology/devices to facilitate or support learning, mobile learning (m-learning). For the purpose of this paper, it is adopted that mobile learning can be defined as facilitating and enhancing the learning process via mobile devices anytime and anywhere, while the use of mobile devices in education (known as m-learning) is considered along with its potential pedagogical benefits such as enhancement of students' motivation, achievement and communication (Baydas \& Yilmaz, 2018).

There is much potential in mobile learning to foster students' learning performances of specific subjects such as science (Bano et al., 2018; Bellou, Papachristos, \& Mikropoulos, 2018), inquiry-based learning (Suárez et al., 2018), collaboration (Fu \& Hwang, 2018), communication, critical thinking (Hwang et al., 2018) and motivation (Chang \& Hwang, 2019). The ubiquity, flexibility, ease of access and diverse capabilities of mobile technologies make them valuable and a necessity in current times. However, these are underutilized assets in science school education and, in parallel, students' interest and engagement in science domain follow a descendant trend (Bano et al., 2018). Reviews/studies on mobile learning in science education (Bano et al., 2018; Crompton et al., 2016; Zydney \& Warner, 2016; Zhai, Zhang, \& Li, 2018) indicated that educational applications, remote experiments and use of sensors can be used to support science learning. Within the context of secondary school science, mobile technology/devices with internet access can facilitate students' online investigations of simulations, video and virtual labs, exercise learner control and personal relevance (e.g., personal inquiry learning) and enhance engagement/participation in the learning process. For example, mobile devices have been successfully used in inquiry-based science learning to facilitate students into their inquiries, support formative or self-assessments and promote problem solving (Nikou \& Economides, 2018a). The smartphone can be a powerful device to collect data, especially with the various sensors that the modern smartphone carries; among the common built-in sensors are the accelerometer, gyroscope, magnetometer, GPS receiver, microphone and camera.

Mobile learning in secondary science education (ages 12 - 18 years old) contexts is still in its infancy in many countries, including Greece. The purpose of this paper is to present a small scale study from Greek secondary education, with examples of mobile-supported science activities. This study was part of the ongoing project "Mobile technology supported learning in Greek secondary educational settings", with scientific responsible one of the authors. For this purpose, next section discusses main studies of science learning with mobile devices. Then, the context of mobile learning in Greece is briefly presented and the small scale study follows. Last section regards the conclusion and implications.

\section{Science Learning with Mobile Devices/Technology}

Recent review in science education (Lin et al., 2019) demonstrated that "educational technology" was the least researched topic within the last two decades, in 
comparison to other topics such as learning-context, learning-conceptions and teaching. This probably reflects the relatively "new" of the field of educational technology; mobile learning can be categorized within this field. Science learning with mobile devices/technology has been investigated in different contexts such as formal educational contexts, semi-formal and informal contexts: formal contexts/settings are defined as traditional institution based learning environments such as school classrooms and laboratories; semi-formal contexts are out-of-classroom contexts pre-determined by a teacher such as school playgrounds, museums and field trips; and informal settings are recreational or everyday spaces chosen by students such as home, trains, cafes, and parks. Overall, fewer mobile learning studies were reported from formal educational contexts.

A recent systematic review of studies published during 2003-2016 (review of empirical evidence regarding mobile learning for science and mathematics school education) investigated research methodologies, foci and outcomes in existing literature, type of mobile technologies and/or apps, as well as the pedagogical approaches reported (Bano et al., 2018). The review focused on the secondary school level (students of ages 12 - 18), because on this level of schooling evidence reported on the lack of engagement of students in mathematics and science. Their results indicated that the studies focused on the effectiveness of mobile technologies/apps for student learning. In science, environmental sciences was the sub-domain that was the focus of most of the studies, followed by geography and physics, while there was a stronger trend of investigating domain specific self-developed apps in science (due to the specificity of the platforms used by the researchers to design/develop the apps or the lack of availability of apps over internet or apps stores). Finally, the most frequently reported pedagogical approach was collaborative learning, followed by inquiry based learning and project/problem based learning.

Crompton et al. (2016) in their systematic review, revealed the trends in mobile learning in science from the year 2000 onward. Major findings include that most of the studies focused on designing systems for mobile learning, followed by a combination of evaluating the effects of mobile learning and investigating the affective domain during mobile learning. The majority of the studies were conducted in the area of life sciences in informal, elementary (5 - 11 years) settings. Mobile devices were used in this strand of science easily within informal environments with real-world connections. Another review (Zydney \& Warner, 2016) examined articles on mobile apps for science learning published from 2007 to 2014. They found that mobile apps for science learning offered a number of similar design features, including technology-based scaffolding, location-aware functionality, visual/audio representations, digital knowledge-construction tools, digital knowledge-sharing mechanisms, and differentiated roles. The most common measured outcome was students' basic scientific knowledge or conceptual understanding. Wang et al. (2015) identified educational functionalities of tablet PCs and generated guidelines to design educational apps for science learning. Following the guidelines, two apps were developed 
and their effects on high school students' science learning were examined. The test results showed a significant improvement in the students' conceptual understanding of the projectile motion and collision of moving objects.

Bellou et al. (2018) carried out a systematic review of empirical research on digital learning technologies and their educational applications in primary and secondary chemistry education. Their results showed that most researchers investigated chemistry topics related to the particulate nature of matter and used digital learning technologies (including mobile technologies), to mainly create and present visualizations of simulations and models of structural elements of matter and their phenomena. Yang and Chang (2017), in Taiwan, conducted an experiment with junior high school students to assess the smartphone to study Geography (smartphone platform with its mobility and GPS capability was considered a useful learning system). The results showed that the students who learned with the proposed system, in the experimental group, achieved better by learning with ubiquitous Geography learning system assistance.

Nikou and Economides (2018b) proposed a series of mobile-based micro-learning and assessment activities for secondary school students of science, and indicated improvement of student learning performance and enhancement of motivation. These researchers (Nikou \& Economides, 2018a) also found that in mobile-assisted inquiry-based science learning, perceived autonomy was the strongest predictor of engagement. Mobile devices incorporating inquiry learning tools can be used as supportive/mediated tools in the classroom; for example, students can investigate scientific phenomena in virtual labs and authentic contexts. Sensor-based mobile tools can be used for collecting and sharing data using phone sensors: accelerometer, gyroscope, light and sound, etc. (Sun \& Looi, 2018). Gonzàlez et al. (2017) in their study with secondary school students used smartphones as measurement devices in physics experiments; the sensors were reliable and accurate enough to permit good measurements. Silva et al. (2018), in Brazil, indicated positive reactions among secondary school students who used mobile devices in formal science lessons, in order to study the human body and the digestive system. Mobile devices with internet access facilitate students' online investigations of simulations, video and virtual labs. Students' collaborative learning skills could be developed when solving science problems together in a mobile technology-supported learning environment.

Zhai et al. (2018), in China, examined ways in which high school students used mobile devices in physics classrooms and after school, as well as the impact of mobile technology use on their physics learning performance and interest. Results indicated that students perceived the mobile devices as very useful for their physics learning (their perceptions were positively correlated with the frequency of use). Both the in-class and after-school duration and frequency of mobile technology use positively influenced students' physics learning achievement and interest. Sun and Looi (2018) explored the crossover between formal learning and learning in informal spaces supported by mobile technology, and 
proposed design principles for educators to carry out a science curriculum. Students were engaged in a series of hands-on activities with mobile devices: collecting, uploading and reviewing data, as well as doing peer assessment. The researchers proposed activities that bridge formal and informal learning spaces and stressed the role played by informal spaces for students' science learning.

In literature, that there are some studies on the topic of mobile learning in formal secondary science education, but these are fewer in comparison to mobile learning studies in higher or elementary education. This topic is not covered in the literature in the Greek context, and since the study took place in Greece, the context is briefly presented below.

\section{The Context of Mobile Learning in Greece}

Regarding the Greek context, the ITU report (2017) ranked Greece among a higher scoring European nation in the Information and Communication Technologies Development Index (IDI); ranking 38th (IDI = 7.23) out of 40 global economies. However, within the Greek formal educational context, the topic of mobile learning is not covered in the literature. The integration of mobile phones in Greek schools is negatively affected by the current legislative framework (Kousloglou, 2017). Greece has a centrally supported school system, where for each subject the same official programme of studies is applied. The official science curriculum for secondary education makes reference to ICT (Information and Communication Technologies), stating, for example, that the science objectives can be facilitated by the use of ICT; the new tools (educational software, internet, visualization tools etc.) multiply the possibilities for students to collect, analyze, visualize and model data, in order for the students to be active participants in the learning process and understand basic principles in science. However, there is no reference to mobile learning or mobile technology/devices (neither for science nor for any other school subject).

The official legislative framework (June 2018), from the Ministry of Education states that within the school environment, students may not own mobile phones or any other electronic device/game that has a system of processing image and sound; the equivalent equipment available at school, is used during the teaching and learning process only under the teacher's supervision; teachers, apart from the available-school owned-electronic devices (computers, laptops, tablets, interactive boards, etc.) can also use their own personal electronic equipment during the lesson, in the context of the educational process in general, in accordance with the safety rules (protection of personal data of pupils and teachers).

Although, mobile phone use is officially banned, during the school intervals (despite the ban), several students "switch on" their mobile phones in order to take photos/videos, send messages or enter social networking sites (Nikolopoulou \& Gialamas, 2017), while within semi-formal settings pre-determined by a teacher (such as school projects, museums and field trips) students are allowed/encouraged to use their mobile devices. Significant causes of restricting 
mobile phone use in schools are the protection of privacy (e.g., pupils taking photos of their peers/teachers in the classroom) and the possibility of sending messages that can lead to cheating. The official ban is a major reason that very few teachers use mobile devices in formal educational contexts.

In parallel, there is a small number of studies regarding teachers' or students' attitudes. Kousloglou and Syrpi (2018) investigated Greek secondary school teachers' perceptions on the use of mobile phones for educational purposes; around $38 \%$ of the sample said they often use mobile phones/tablets for educational purposes, while $75 \%$ of respondents expressed willingness to integrate mobile devices in the learning process (they said, it is likely to increase students' interest/motivation), if the law allows it. When teachers allow their students to use mobile phones, this happens under supervision (e.g., in clubs, during school projects, physics experiments or extra-curricular activities). Regarding Greek secondary school students, studies indicated positive attitudes and high self-efficacy towards mobile devices' usage (Nikolopoulou \& Gialamas, 2017) and little self-perceived mobile phone dependence (Nikolopoulou \& Gialamas, 2018). Another study (Nikolopoulou, 2018) revealed secondary students' positive perceptions toward mobile learning acceptance and high mobile device usage in informal settings; the mobile phone was the predominant device which is used daily by almost all students, $83 \%$ of the sample goes online via a mobile device several times per day, and $65 \%$ described themselves as advanced mobile device users.

Within this context, a few teachers take initiatives and allow their students to use mobile devices in the classroom, for educational purposes (since the official curriculum makes no reference to mobile learning). Such an initiative is described in the following section.

\section{A Small Case Study: Mobile Learning Activities in Science Lessons}

\subsection{The Aim of the Study}

This small scale study was part of the ongoing research project "Mobile technology supported learning in Greek secondary educational settings", initiated by one of the authors. The aim was to identify and describe mobile supported/mediated learning activities in secondary science classes, without any artificial intervention by the researcher. Thus, the activities presented below were undertaken under the initiative of two physics teachers who work in two different schools. One school was located in Attica (in this school took place the first example/activity) and the other was located in North Greece (at this school took place the remaining activities). These two schools were chosen because they are included in a larger project initiated by the first author. Both school principals accepted the initiatives, without raising any objections to the implementation of the learning activities. The sample and the procedure are described under each activity. 


\subsection{Measuring with Accuracy the Time with Mobile Phones}

The participants were 78 students aged 12 - 13 years old (attending the $1^{\text {st }}$ year of secondary school), and the activity was implemented during the academic year 2018-2019. Physics was introduced as a subject in the first year of secondary schools during the academic year 2014-15. The relatively "new" school physics textbook includes an experimental activity where students are asked to measure the time of ten oscillations, five times, 1) with analog and 2) with digital watch/clock (in the appropriate units of time); and then to calculate the mean value for the time of one oscillation, as it resulted by using different devices. For this activity, students worked in groups of 3 - 4, in physics lab, and each group was asked to use the "stopwatch" tool (rather than the stopwatches of the lab, which are in shortage) and then the "calculator" tool of their mobile phones. The young students participated in the experiment with joy; they were motivated and stayed concentrated on the activity. They said they enjoyed using their mobiles throughout the lesson, even if the school rules do not allow their usage. Table 1 shows the percentage of students' responses with regard to their contentment with the activity. The majority of students (62.8\%) reported they were very much interested in the activity, while they also expressed contentment working in groups (64.1\%). Next session included interpretation of the results; i.e., a discussion about different devices for measuring the time, and their accuracy.

\subsection{Studying the Average Speed Using Mobile Phones and Tablets}

The experimental process took place at the beginning of the academic year 2018-19. The participants were 90 students aged 13 - 14 years old (2nd year of secondary school). One week before the activity, the students were informed about this initiative and they discussed about the appropriate usage of mobile phones and the relevant school rules. A demonstration of the capabilities of the four application tools (distance, speed gun, calculator, stopwatch) that they would use during the experimental process took place, and students were asked to install the application (during the week possible problems regarding the installment were briefly resolved). The software used was smarttools (https://play.google.com/store/apps/details?id=com.pcmehanik.smarttoolkit).

Smarttools is software for Android that turns the mobile device into a multi-tool with forty different possibilities; the software includes many different tools that can be used to support science in different age levels. There is a free version of the software, it is simple to use and it has an attractive interface for young people. The performance of the experiment took place during two teaching sessions (the duration of a lesson/session is 45 minutes).

During the first lesson/session, the students worked in groups of $4-5$, and had to complete relevant worksheets; initially, they completed their hypotheses and then, they measured a specific distance in two ways, by using the mobile/tablet distancer and by using a classic measurement tape; the measurements were repeated three times (by each group) so as to calculate and use the mean 
Table 1. Percentage (\%) of students' responses with regard to their contentment with the activity $(\mathrm{n}=78)$.

\begin{tabular}{cccc}
\hline How satisfied were you with regard to & Little & Moderate & Very much \\
\hline the interest of the activity & 15.4 & 21.8 & 62.8 \\
group work & 16.7 & 19.2 & 64.1 \\
the opportunity to cooperate with peers & 16.7 & 23 & 60.3 \\
\hline
\end{tabular}

values of the measurements. During the next activity, students used a little toy-car to measure the time it takes to travel the distance they had already measured; the timer of the mobile/tablet was used; the experiment was repeated again three times and the measurements were recorded in a worksheet.

During the second lesson/session, students used their mobile/tablet speedometer to measure the average speed of the car as it ran the distance. Afterwards, they calculated the average speed from the distance and time measurements of the previous lesson, they turned the speed they found with the help of their speedometer, from $\mathrm{Km} / \mathrm{h}$ to $\mathrm{m} / \mathrm{sec}$ and compared the values found via the two different methods. The students showed enthusiasm and great willingness to participate in the experiment, and they collaborated in groups (Figure 1). They commented that the two hours of experimental lessons passed quickly, and they understood better the concept of the average speed.

Table 2 shows the percentage of students' responses with regard to their contentment with the activity. The majority of students (84.5\%) reported they were very much interested in the activity, while they also expressed contentment working in groups (82.3\%). Indeed, they actively participated in the whole process, as described in Kousloglou (2017). At home, students used their mobile phone to download and study the "smarttools" program. The majority of students kept "smarttools" on their mobile phones and continued to experiment with the available tools.

\subsection{Studying the Induction Electrification with Virtual Lab}

Participants were 90 students aged $14-15$ years old ( $3^{\text {rd }}$ year of secondary school), who studied the induction electrification (within the unit of electricity) with the use of virtual lab (Figure 2); it provides the ability to represent micro-level/scale phenomena that are virtually impossible to replicate in other ways. The virtual lab used was the "Balloons and Static Electricity"; from the University of Colorado's virtual labs (phet-simulations), which is accessible via Googleplaystore. The installation was made on a tablet and then it was shared with the other tablets through the SHAREit app. By using this application, the students smashed virtual balloons into the virtual sweater and then stuck them on the virtual wall; observing the electron movement of the wall and the attraction of the balloons by it. Before using the virtual lab, students had already carried out some induction electrification experiments using simple everyday materials. 
Table 2. Percentage (\%) of students' responses with regard to their contentment with the activity $(\mathrm{n}=90)$.

\begin{tabular}{cccc}
\hline How satisfied were you with regard to & Little & Moderate & Very much \\
\hline group work & 3.3 & 12.2 & 84.5 \\
the interest of the activity & 5.5 & 12.2 & 82.3 \\
the opportunity to cooperate with peers & 5.5 & 12.2 & 82.3 \\
the assistance of the worksheers & 7.7 & 16.7 & 75.6 \\
\hline
\end{tabular}

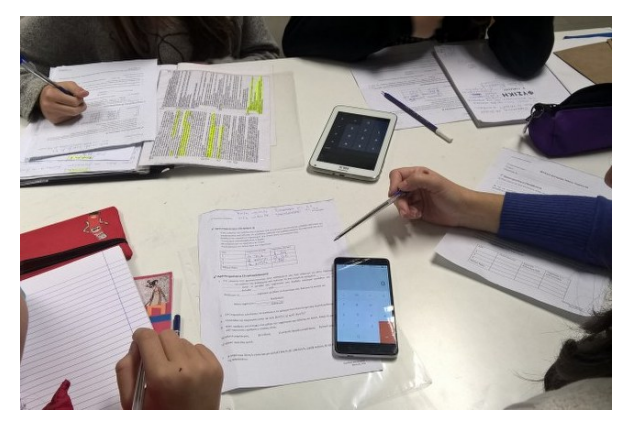

Figure 1. Students working in groups, studying average speed with mobile devices.

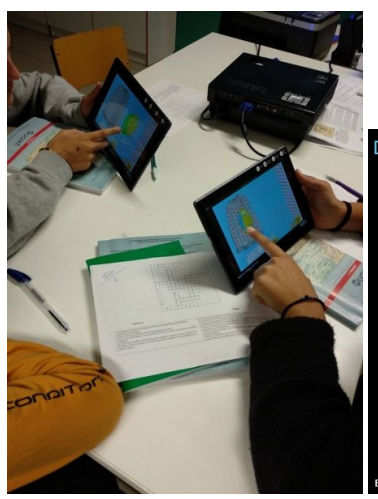

(a)

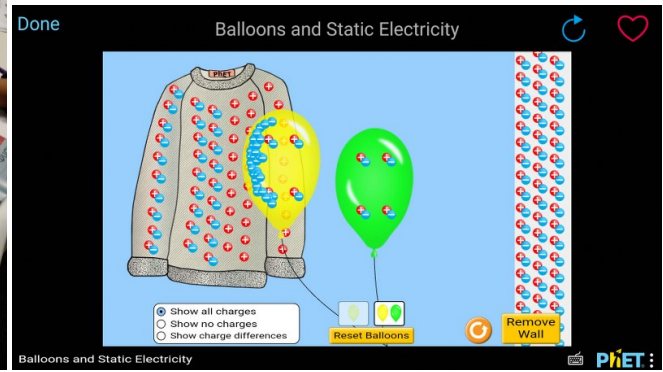

(b)

Figure 2. Studying electricity with tablets and screenshot from the app.

\subsection{Studying the Electrical Charge within the Atom, with Augmented Reality and Virtual Labs}

Participants were the same 90 students aged 14 - 15 years old (3rd year of secondary school), as in the previous example. As part of the teaching of the electrical charge within the atom, the students used the mobile phones and tablets distributed to them for the purpose of building the atoms and ions of various chemical elements. During construction, students could calculate the deficit or the excess of negative/positive electric charge. The software installed was PhEt Simulations, the University of Colorado (installing from GooglePlay). The virtual workshop used was "Build an Atom". Then the students had an "augmented reality" experience of the atom, using the "iScienceAR" software (GooglePlay: https://play.google.com/store/apps/details?id=com.redfrog.isciencear) and the 
corresponding book

(https://www.amazon.com/iScience-Elements-Explosive-Experiments-iExplore/ $\mathrm{dp} / 1783121122)$ which is also available in the Greek edition; they "got in their hands" various chemical elements (see Figure 3). The duration of the experiment was approximately 20 minutes.

\section{Conclusion}

Mobile technology-supported science learning is a topic under investigation. Studies on mobile learning in science education indicated that different tools/applications can be used to support science learning and that mobile devices with internet access can facilitate students' online investigations of, for example, simulations, video and virtual labs. This study adds to the body of evidence of mobile-supported science activities in secondary classrooms. The results of the small scale study in the Greek context were in some agreement with earlier research which indicated that mobile technology use enhances students' interest/motivation (Zhai et al., 2018; Chang \& Hwang, 2019), positive reactions (Silva et al., 2018) and collaboration (Fu \& Hwang, 2018). Taken into account that secondary school students' interest and engagement in science domain follow a descendant trend (Bano et al., 2018), mobile devices could be used as a learning tool to support science lessons, where appropriate (this will be decided by teachers, whose role is discussed in implications). The topic is not covered within the context of Greek secondary education, and this is also linked to the ban of mobile devices/phones in classrooms. The small scale study which was carried out without artificial intervention indicated illustrations of classroom activities in formal science education contexts; the activities were based solely on teachers' initiatives. These could constitute examples of classroom practices for other teachers who wish to support their science lessons with mobile technology/devices. The above have implications for education policymakers, teachers and students.

Regarding educational policies, as the curriculum does not provide instructions for using mobile technology in classrooms, their use (and consequently mobile supported science learning activities) could be a subunit of ICT use-integration. Science units of the official curriculum could be enriched/supported with appropriate mobile applications, under the ICT umbrella. The increasing ownership and usage of mobile devices are not a guarantee for learning. Mobile technologies and wireless internet access offer opportunities for learning under conditions (way of integration, pedagogical strategies, appropriateness of software etc.). The role of the teachers is very essential as they, for example, will design, implement and evaluate appropriate learning activities for their students. This has implications for teachers' in-service professional development, as well as for pre-service training. Appropriate training is expected to help teachers enhance their mobile pedagogical approaches, when integrating mobile technologies to support students' learning. For science learning, the mobile environment 


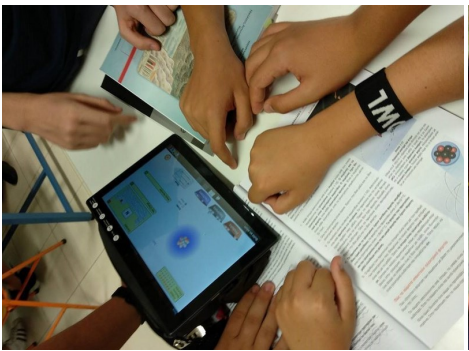

(a)

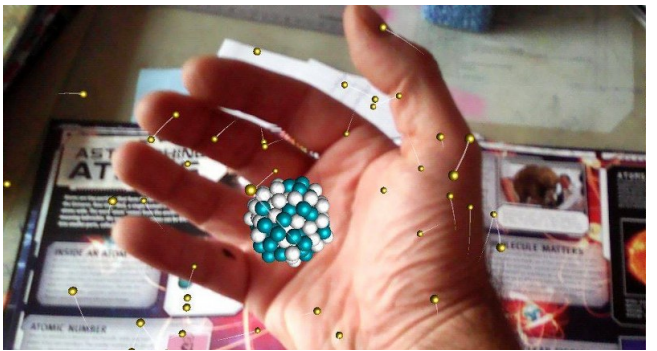

(b)

Figure 3. Studying the electrical charge within the atom, with Augmented Reality and Virtual Labs.

is a challenge to provide students the skills and knowledge to be informed and engaged online learners. In classrooms, students' need for autonomy could be met in an autonomy supported mobile learning environment that provides appropriately designed learning activities. Besides, it is essential that students will be informed about the dangers and the potential benefits of using mobile phones in the classroom (Joyce-Gibbons et al., 2018). The presence of mobile devices in schools should not be ignored, while research needs to also consider ethical issues (Wishart, 2018). Taken into account the above, some of our suggestions include:

- to investigate small scale practices of teachers who try out appropriate uses of mobile devices; e.g., to identify teachers who are willing to use mobile phones as complementary tools to more traditional teaching

- to explore teachers' and students' perceptions regarding mobile technology in classrooms (perceptions regarding acceptance, benefits, disadvantages etc.)

- to develop school policies that focus to devices' usage, security and behavioral issues

- to initiate discussions about mobile phone usage for learning purposes

- (apart from students) to also inform parents of school policy and of the learning potential of mobile devices.

A major barrier associated with the implementation of mobile technology learning is e-safety, e.g., the security of personal data, information, images, and video on mobile devices (Whyley, 2018). This is an essential issue to be considered, and students need to be informed about the rules before using any mobile device in formal educational settings. Mobile devices are relatively new and evolving; the extensive use of the internet via mobile devices/phones and the development of new features and functions make it crucial for this topic to be examined throughout the years. Mobile learning continues to spread, thus further research regarding mobile technology supported learning is needed. This will help science educators to expand their knowledge and skills on how to embrace these technologies. In parallel, different factors may impact on students' learning in the mobile technology-supported environment; for example, the design features/functions of the mobile learning environment, students' and teachers' perceptions, and mainly teachers' pedagogical strategies/practices. This study's li- 
mitations include that these factors were not examined. As a consequence, such factors are useful to be investigated in science education, with students of different ages. Future research is also suggested to investigate the impact of mobile technology-supported learning on students' motivation/engagement, performance and participation of learning science concepts/skills, and to also take into account students' prior mobile technology experiences (e.g., those acquired in informal settings).

\section{Conflicts of Interest}

The authors declare no conflicts of interest regarding the publication of this paper.

\section{References}

Bano, M., Zowghi, D., Kearney, M., Schuck, S., \& Aubusson, P. (2018). Mobile Learning for Science and Mathematics School Education: A Systematic Review of Empirical Evidence. Computers \& Education, 121, 30-58. https://doi.org/10.1016/j.compedu.2018.02.006

Baydas, O., \& Yilmaz, R. (2018). Pre-Service Teachers' Intention to Adopt Mobile Learning: A Motivational Model. British Journal of Educational Technology, 49, 137-152. https://doi.org/10.1111/bjet.12521

Bedesem, P. L., \& Arner, T. (2019). Mobile Learning in and out of the K-12 Classroom. In D. B. A. Mehdi Khosrow-Pour (Ed.), Advanced Methodologies and Technologies in Modern Education Delivery (pp. 839-849). Hershey, PA: IGI Global. https://doi.org/10.4018/978-1-5225-7365-4.ch065

Bellou, I., Papachristos, N. M., \& Mikropoulos, T. A. (2018). Digital Learning Technologies in Chemistry Education: A Review. In D. Sampson, D. Ifenthaler, J. Spector, \& P. Isaías (Eds.), Digital Technologies: Sustainable Innovations for Improving Teaching and Learning (pp. 57-80). Cham: Springer International Publishing. https://doi.org/10.1007/978-3-319-73417-0_4

Chang, C.-Y., \& Hwang, G.-J. (2019). Trends in Digital Game-Based Learning in the Mobile Era: A Systematic Review of Journal Publications from 2007 to 2016. International Journal of Mobile Learning and Organisation, 13, 68-90. https://doi.org/10.1007/978-3-319-73417-0_4

Crompton, H., Burke, D., Gregory, K. H., \& Gräbe, C. (2016). The Use of Mobile Learning in Science: A Systematic Review. Journal of Science Education and Technology, 25, 149-160. https://doi.org/10.1007/s10956-015-9597-x

Fu, Q.-K., \& Hwang, G.-J. (2018). Trends in Mobile Technology-Supported Collaborative Learning: A Systematic Review of Journal Publications from 2007 to 2016. Computers \& Education, 119, 129-143. https://doi.org/10.1016/j.compedu.2018.01.004

Gonzàlez, M. A., Gonzàlez, M. A., Martin, M. E., Llamas, C., Martínez, Ó., Vegas, J., Herguedas, M., \& Hernàndez, C. (2017). Teaching and Learning Physics with Smartphones. In Blended Learning: Concepts, Methodologies, Tools, and Applications (pp. 866-886). Hershey, PA: IGI Global. https://doi.org/10.4018/978-1-5225-0783-3.ch044

Hwang, G.-J., Lai, C.-L., Liang, J.-C., Chu, H.-C., \& Tsai, C.-C. (2018). A Long-Term Experiment to Investigate the Relationships between High School Students' Perceptions of Mobile Learning and Peer Interaction and Higher-Order Thinking Tendencies. Educational Technology Research and Development, 66, 75-93. 
https://doi.org/10.1007/s11423-017-9540-3

International Telecommunication Union (ITU) (2017). Measuring the Information Society Report 2017. Geneva: ITU.

https://www.itu.int/en/ITU-D/Statistics/Documents/publications/misr2017/MISR2017 =Volume1.pdf

Joyce-Gibbons, A., Galloway, D., Mollel, A., Mgoma, S., Pima, M., \& Deogratias, E. (2018). Mobile Phone Use in Two Secondary Schools in Tanzania. Education and Information Technologies, 23, 73-92. https://doi.org/10.1007/s10639-017-9586-1

Kousloglou, M. (2017). Utilization of Embedded Sensors of Smartphones in Physics Science Experiments: A Case Study in Physics, in 2nd Year of a Secondary School. In 9th Panhellenic Conference "Use of ICT in the Teaching Process" (pp. 447-460). Syros: YPETH. (In Greek)

Kousloglou, M., \& Syrpi, M. (2018). Perceptions of Secondary School Teachers on the Use of Handheld Devices in Schools as Learning Tools. In 5th Pan-Hellenic Educational Conference of Central Macedonia "ICT Use and Integration in Educational Practice" (pp. 39-62). Thessaloniki: PEEMD. (In Greek)

Lin, T.-J., Lin, T. C., Potvin, P., \& Tsai, C.-C. (2019). Research Trends in Science Education from 2013 to 2017: A Systematic Content Analysis of Publications in Selected Journals. International Journal of Science Education, 41, 367-387. https://doi.org/10.1080/09500693.2018.1550274

Nikolopoulou, K. (2018). Mobile Learning Usage and Acceptance: Perceptions of Secondary School Students. Journal of Computers in Education, 5, 499-519. https://doi.org/10.1007/s40692-018-0127-8

Nikolopoulou, K., \& Gialamas, V. (2017). High School Pupils' Attitudes and Self-Efficacy of Using Mobile Devices. Themes in Science \& Technology Education, 10, 53-67.

Nikolopoulou, K., \& Gialamas, V. (2018). Mobile Phone Dependence: Secondary School Pupils' Attitudes. Education and Information Technologies, 23, 2821-2839. https://doi.org/10.1007/s10639-018-9743-1

Nikou, S. A., \& Economides, A. A. (2018a). Motivation Related Predictors of Engagement in Mobile-Assisted Inquiry-Based Science Learning. In IEEE Global Engineering Education Conference (pp. 1222-1229). Piscataway, NJ: Institute of Electrical and Electronics Engineers. https://doi.org/10.1109/EDUCON.2018.8363369

Nikou, S. A., \& Economides, A. A. (2018b). Mobile-Based Micro-Learning and Assessment: Impact on Learning Performance and Motivation of High School Students. Journal of Computer Assisted Learning, 34, 269-278. https://doi.org/10.1111/jcal.12240

Silva, I., Lotthammer, K. S., Silva, K., Viegas, L. M., Marcelino, Z., Silva Juarez, B., \& Bilessimo, S. (2018). Use of Mobile Devices in Science Education in a Brazilian Public School Located in a Region of High Social Vulnerability: A Case Study. In Mobile Applications and Solutions for Social Inclusion (pp. 109-136). Hershey, PA: IGI Global. https://doi.org/10.4018/978-1-5225-5270-3.ch005

Suárez, A., Specht, M., Prinsen, F., Kalz, M., \& Ternier, S. (2018). A Review of the Types of Mobile Activities in Mobile Inquiry-Based Learning. Computers and Education, 118, 38-55. https://doi.org/10.1016/j.compedu.2017.11.004

Sun, D., \& Looi, C.-K. (2018). Boundary Interaction: Towards Developing a Mobile Technology-Enabled Science Curriculum to Integrate Learning in the Informal Spaces. British Journal of Educational Technology, 49, 505-515. https://doi.org/10.1111/bjet.12555

Wang, J.-Y., Wu, H.-K., Chien, S.-P., Hwang, F.-K., \& Hsu, Y.-S. (2015). Designing Ap- 
plications for Physics Learning: Facilitating High School Students' Conceptual Understanding by Using Tablet PCs. Journal of Educational Computing Research, 51, 441-458. https://doi.org/10.2190/EC.51.4.d

Whyley, D. (2018). Barriers to Mobile Learning Advancements in the United Kingdom. In J. Voogt, G. Knezek, R. Christensen, \& K.-W. Lai (Eds.), Second Handbook of Information Technology in Primary and Secondary Education (pp. 807-816). Berlin: Springer International Publishing AG. https://doi.org/10.1007/978-3-319-71054-9_53

Wishart, J. (2018). Mobile Learning in Schools: Key Issues, Opportunities and Ideas for Practice. Abingdon-on-Thames: Routledge. https://doi.org/10.4324/9781315536774

Yang, H.-C., \& Chang, W.-C. (2017). Ubiquitous Smartphone Platform for K-7 Students Learning Geography in Taiwan. Multimedia Tools and Applications, 76, 11651-11668. https://doi.org/10.1007/s11042-016-3325-2

Zhai, X., Zhang, M., \& Li, M. (2018). One-to-One Mobile Technology in High School Physics Classrooms: Understanding Its Use and Outcome. British Journal of Educational Technology, 49, 516-532. https://doi.org/10.1111/bjet.12539

Zydney, J. M., \& Warner, Z. (2016). Mobile Apps for Science Learning: Review of Research. Computers and Education, 94, 1-17.

https://doi.org/10.1016/j.compedu.2015.11.001 